Original Research Paper

\title{
Virtual Assessment of Air Pollution Dispersion from Anthropogenic Sudden Explosion
}

\author{
Marvel Lola Akinyemi, Moses Eterigho Emetere and Mojisola Rachel Usikalu \\ Department of Physics, Covenant University Canaan Land, P.M.B 1023, Ota, Nigeria
}

\section{Article history}

Received: 25-06-2015

Revised: 05-04-2016

Accepted: 08-04-2016

Corresponding Author: Marvel Lola Akinyemi Department of Physics, Covenant University Canaan Land, P.M.B 1023, Ota, Nigeria

Email:

moses.emetere@covenantuniversity.edu.ng

\begin{abstract}
The control of air pollutants from anthropogenic sources seems almost impossible due to numerous influencing factors present in the atmosphere. In this study, we carried out a virtual mathematical experimentation using Math CAD, Mat lab and analytical approximation to estimate the dimensional impact of initial pollutant plume cloud from a sudden volcanic blast and the dynamics of its wind field. The high point of the experimentation is the period of the first one-tenth of a second ( 1 decisecond) to $1 \mathrm{~min}(60 \mathrm{~s})$ of the blast at the point source. We also assessed the long range air pollution dispersion within the first 1 to $10 \mathrm{~min}$ of plume cloud released under practical assumptions. The model revealed a plume cloud impact of $6.8 \times 10^{7} \mathrm{\mu gm}^{-3}$ in the first 1 millisecond $(0.01 \mathrm{~s})$ which decayed suddenly to a value of $1.7 \times 10^{7} \mu \mathrm{gm}^{-3}$ in the first 1 deci-second $(0.1$ $\mathrm{s})$. The impact concentration at the point source by the end of the first second

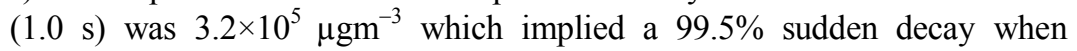
compared with $0.01 \mathrm{~s}$ concentration value at the emission point source. It is observed that air pollutants released from explosives/blasts get transported into the atmosphere in the first few seconds by forceful injection instead of by gradual dispersion as is the case with normal air pollutants plume releases. A mathematical control process was propounded (which is still subject to further research) to reduce the quick flow of air pollutants.
\end{abstract}

Keywords: Pollutant Plume, Forceful Injection, Gradual Dispersion, Impact Concentration

\section{Introduction}

Air pollution is undoubtedly one of the signatures of volcanic eruption (Bluth et al., 1992; Read et al., 1993). The environmental impact of air pollution depends on its ability to produce adverse significant effects on life forms and material substances. In a broader form, gaseous air pollutants include all the gases that are found in the atmosphere above their normal ambient levels, while particulates include both solid and liquid particles that become airborne (Seinfeld, 1986; Hopke, 2009; DiGiovanni and Fellin, 2006; Smodis, 2007; Smith et al., 2001). Before there is an eruption, there is an explosion which is usually characterized by sudden release of energy that produces a sudden volume expansion $(\mathrm{dV})$ of the conveying material due to large changes in pressure $\mathrm{dP}$ within the shortest possible time $(\mathrm{dt})$. This causes pressure waves in the local medium in which they occur. These pressure waves can either be subsonic or supersonic (Bazarov et al., 1991; Slotnick, 2008); likewise, the explosion can be natural or anthropogenic. The intensity of an explosion $\left(I_{\text {exp }}\right)$ therefore is proportional to the magnitude of $\frac{d P}{d t}$ and $\frac{d V}{d t}$ :

$$
\begin{aligned}
& I_{e x p} \alpha \frac{d P}{d t} \\
& I_{e x p} \alpha \frac{d V}{d t}
\end{aligned}
$$

Walker (1980) on his part suggested some parameters for estimating the scale of explosive eruptions, namely, magnitude (determined from the volume ejected); intensity (determined from volume ejeted per unit time and also from the column height and calculated muzzle velocities); dispersive power (determined by column height); violence (released rate of kinetic energy as related to instantaneous intensity rather than sustained eruptions). 
Air Pollutants from Volcanic Eruptions and Anthropogenic Sudden Explosion

Volcanic Explosion Mechanisms (VEM) can be categorized under four subheadings: First, the magnitude of eruption in terms of mass and volume of volcanic matters ejected into the atmosphere; second, the intensity of the explosion in terms of noise and vibration on the immediate environment; thirdly, the duration of eruption; and fourthly, the extent of particulate dispersion both horizontally and vertically within the shortest possible time of eruption. Past researchers have employed various scientific parameters to study and elucidate each of these mechanisms (Tupper et al., 2004; Tupper and Wunderman, 2009; Emetere and Akinyemi, 2013; Emetere, 2013).

Parts of nature largest sources of sudden explosions are volcanic explosive eruptions. Volcanic explosion can be in the form of sudden eruption of hot lava and thick smoke unto the surface, sudden release of hot spring of water and steam also known as Geysers and violent vibration of the earth crust to a certain depth also known as earth quake. The depth of the vibration determines the magnitude of the earth quake (Devine et al., 1984; Arya, 1999) which was mathematically structured by Emetere (2012) as:

$M=\frac{2}{3} \log \left(\frac{k^{2}}{2 \omega}\right) \cdot\left(\frac{\rho_{s}}{\rho_{b}}\right)^{2}-7.87$

Where:

$k=$ The hydraulic conductivity

$M=$ The magnitude of the earthquake

$\rho_{s}=$ The soil particle density

$\rho_{b}=$ The soil bulk density

$\omega=$ The circular frequency

$k=$ The thermal diffusivity

Aside the vibration and the eruption of hot lava, volcanic explosion was discovered to be distinctly harmonic and possess distinct spectral peaks at periods of seconds (Hagerty et al., 2000; Emetere, 2012). Major volcanic eruptions eject large amounts of particulate matter in form of ashes, gases such as carbon diode $\left(\mathrm{CO}_{2}\right)$, sulphur dioxide $\left(\mathrm{SO}_{2}\right)$ and other gases into the atmosphere. Some of these pyroclastic materials get transported to high altitudes and stay there for months or several years to impact the global climate system (Neff, 1998). This implies that materials from volcanic eruptions easily transcend the lowest portion of atmosphere which is the troposphere into the stratosphere (Groisman, 1992; Kane, 1998).

Sudden volcanic eruption is characterized with very fast air pollutants movement. For example, in about three weeks, the sulfate cloud generated by the volcanic eruption of Mount Pinatubo was reported to have travelled the globe and crossed the equator (McCormick and Swissler, 1983). The mathematical expression gives the discharge rate $Q$ at which magma is ejected out of a volcano conduit of average radius $R$ and length $L$ as:

$Q=\frac{\pi R^{4} P}{8 \mu L}$

Here $\mu$ is the viscosity of the magma and $P$ is the pressure inside the magma chamber.

In an explosive blast, a shock wave is produced when the rate of combustion of the explosive material creates a sharp pressure gradient. The amount of chemical potential energy is converted to kinetic and heat energy during the process of an explosion varies. Materials such as trinitrotoluene (TNT) are characterized by a large amount of chemical potential energy that is nearly instantaneously converted to kinetic and heat energy. The resulting generated speed in the medium is approximately $6900 \mathrm{~ms}^{-1}$ for TNT. This results in very high kinetic energy of approximate value of $4.7 \mathrm{kJg}^{-1}$ or 4.7 $\mathrm{MJkg}^{-1}$. According to Neff (1998), the chemical reaction in an average TNT explosion is typically $90 \%$ complete in between $10^{-9}$ and $10^{-6} \mathrm{sec}(1$ nanosecond to 1 microsecond) and as the energy of the blast dissipates with increasing distance from the blast, the wave dissipates into a sound wave resulting in loud blast.

Like volcanic eruptions, anthropogenic induces sudden explosions that generate extreme forces and pressures which propagate the air pollutants emitted to great altitude in the shortest possible period of time at the moment of blast. This causes instant massive displacement and dispersion of other atmospheric constituents. Besides the generation of shock waves by an explosive blast which causes devastations and destructions, there is usually the accompanying sudden release of air pollution plume.

The air pollutants sudden injection into the atmosphere coupled with the gradual dispersion which later follows and subsequent atmospheric reactions from this initial pollutant cloud is what this study focuses on. The study will also look at the mathematical dynamics of the strong wind; explain the significance of the wind speed to life-forms and estimate the long range plume cloud dispersion.

\section{Theoretical Derivation of Particulate Dynamics During Volcanic Explosion}

In order to efficiently account for the movement of volcanic ash clouds dispersion, the following assumptions were made: (a) eruption is weak in a strong wind field; (b) the bulk density of the ash-gas mixture equals that of the surrounding air; (c) advection, diffusion and 
sedimentation do not significantly affect the level of concentration; (d) the transport of the plume is sudden.

Balmforth et al. (2005) gave the governing equation of conservation of momentum during volcanic explosion as:

$$
\begin{aligned}
& \rho\left(U_{t}+U U_{x}+V U_{y}\right)=-P_{x}+\rho \mu\left(U_{x x}+U_{y y}\right) \\
& \rho\left(V_{t}+U V_{x}+V V_{y}\right)=-P_{y}+\rho \mu\left(V_{x x}+V_{y y}\right)
\end{aligned}
$$

This maintains continuity at $U_{x}+U_{y}=0$ where $\rho$ is the fluid density, $\mu$ is the viscosity, $U=V$ velocity field, $P$ is the pressure.

Substituting for $\rho \mu$ in Equation 3 and 4 gives:

$$
\frac{\rho\left(U_{t}+U U_{x}+V U_{y}\right)+P_{x}}{U_{x x}+U_{y y}}=\frac{\rho\left(V_{t}+U V_{x}+V V_{y}\right)+P_{y}}{V_{x x}+V_{y y}}
$$

Applying the condition for continuity, Equation 5 generates:

$$
\frac{m\left(U_{t}+U U_{x}+V U_{y}\right)+\beta P_{x}}{U_{x y}}=\frac{m\left(V_{t}+U V_{x}+V V_{y}\right)+\beta P_{y}}{V_{x y}}
$$

where, $\beta$ is the volume of the fluid and $\mathrm{m}$ is the mass of the fluid:

$$
\frac{\alpha\left(U_{t}+U U_{x}+V U_{y}\right)}{U_{x y}}+\frac{\beta_{t} P_{t x}}{U_{y}}=\frac{\alpha\left(V_{t}+U V_{x}+V V_{y}\right)}{V_{x y}}+\frac{\beta_{t} P_{t}}{V_{x}}
$$

where, $a=m_{t}$, the emission rate of particulate of the volcanic explosion. Equation 7 generated two equations as:

$$
\begin{aligned}
& \frac{\beta_{t} P_{t}}{V_{x}}-\frac{\beta_{t} P_{t}}{U_{y}} \propto I_{\exp } \\
& \frac{\alpha\left(U_{t}+U U_{x}+V U_{y}\right)}{U_{x y}}-\frac{\alpha\left(V_{t}+U V_{x}+V V_{y}\right)}{V_{x y}} \propto I_{\exp }
\end{aligned}
$$

where, $I_{\text {exp }}$ is the intensity of the explosion. Equation 8 and 9 are known as the elements of volcanic explosion. From Equation 8, the intensity of a volcanic explosion is directly proportional to the rate of change of volume and pressure. This is in agreement with Bazarov et al. (1991) and Slotnick (2008). Beyond the idea of Equation 8 which shows that the volcanic intensity is also inversely proportional to the dispersion rate of the particulate, Equation 9 reveals that the intensity of a volcanic explosion is directly proportional to the emission rate of the particulate. Further analyses of Equation 9 are therefore paramount to determine the effects of velocity on the plume dispersion and the role of intensity in the impact of the vibration at the source. From Equation 9:

$$
k\left(\frac{\alpha\left(U_{t}+U U_{x}+V U_{y}\right)}{U_{x y}}-\frac{\alpha\left(V_{t}+U V_{x}+V V_{y}\right)}{V_{x y}}\right)=I_{\exp }
$$

where, $k$ represents group of constants. The combination of the constants that make up constant $(k)$ is still subject to further research. Integrating with respect to y yields, on the initial condition that $x \rightarrow 0$ :

$$
\begin{aligned}
& \left(I_{\text {exp }}+\frac{\alpha\left(V_{t}+U V_{x}+V V_{y}\right)}{V_{x}}\right) \\
& U_{x}=\alpha k\left(U_{t}+U U_{x}+V U_{y}\right) y-\alpha k\left(U_{t}+V U_{y}\right) y \\
& \left(I_{\exp }+\frac{\alpha\left(V_{t}+U V_{x}+V V_{y}\right)}{V_{x}}\right) U_{x}=\alpha k U U_{x} y \\
& \left(I_{\exp }-\alpha k U y-\alpha U\right) V_{x}=\alpha V_{t}+V_{y}
\end{aligned}
$$

Applying the separation of variable, that is, $V(x, y, t)=$ $X(x) Y(x) T(t)$ gave the solution as:

$V(x, y, z, t)=A e^{\frac{k x}{I_{\exp }-\alpha k U y-\alpha U}} e^{\frac{c t}{\alpha}} e^{(k-c) y}$

where, $A=C_{1} C_{2} C_{3}, k$ and $c$ are constants.

To solve Equation 14 using the inverse problem (Perovich, 2001), the Special Trans Function Theory (STFT) was used whose probability is given as:

$$
\begin{aligned}
P(t) & =\int_{0}^{t} A e^{-\vartheta t} d t=1-e^{-\vartheta t}, t>0 \\
\vartheta & =\left(\frac{k x}{I_{\text {exp }}-\alpha k U y-\alpha U}\right)\left(\frac{c t}{\alpha}\right)((k-c) y), \text { we split } \vartheta \text { to }
\end{aligned}
$$

account for the constants:

$$
\begin{gathered}
0=\alpha I_{\exp }-\alpha^{2}(k U y-U) \\
\alpha=\frac{I_{\exp }}{(k U y-U)} \\
0=c t k x(k-c) y \\
k=c
\end{gathered}
$$

Here, we assume a probability that no failure will occur in the technical system within a short time interval.

$P(t)=1-\int_{0}^{t} A e^{-\vartheta t} d t=e^{-\vartheta t}, t>0$ 
Its approximation is given as:

$P_{a}(t)=1-\int_{0}^{t} A e^{-\vartheta t} d t=e^{-\vartheta t} \approx 1-\vartheta t, t>0$

$\vartheta$ is verified using the pressure data acquired from the 'Mars 96 sensor' to analyze a large tick at midnight within a week as shown in Fig. 5.

\section{Design of Virtual Experimentation}

A MathCAD model of sudden air pollutants released at different area spread was carried out. It was treated as a sudden plume cloud release and not as a continuous smoke release. Momentum and kinetic energy changes are the dominant factors for detonations, whereas transport and dispersion processes are more relevant for the air pollution generated. The self-similarity of the solution at different scales was an important characteristic of the plume wave profile generated by the model.

Within the scope of the study, the explosive blast waves were treated as identical to volcanic eruption except for scaling in magnitude and duration. The activation of the model was made to be proportional to the mass and the initial velocity, which also implies the embedding of the initial kinetic energy of the blast into the model.

\section{Results}

Figure 1 shows that air pollutants generated under a normal gradual circumstance get dispersed depending on the prevalent atmospheric conditions and local wind speed at the time of release. The intensity of explosion was initially linearly proportional to both the pressure and volume of air pollutant until different influencing factors like atmospheric stability, mixing height and atmospheric ventilation index set into changing its behavior to a negative parabolic shift with respect to time. This idea is in line with the analysis of the volcanic eruption of Mount Pinatubo (McCormick and Swissler, 1983; Bluth et al., 1992; Read et al., 1993). Figure 2 shows the atmospheric changes (stable atmosphere to turbulence atmosphere) which occur at spilt seconds before and after the volcanic explosion. A stable atmosphere is one that is strongly resistant to change, while atmospheric turbulence results in significant displacement of air parcels both in horizontal and vertical directions. Thus, an unstable atmosphere helps to disperse air pollutants from the emission point source fast.

However, this study revealed that air pollutants generated from sudden explosion/blast get dispersed very fast from emission point source due to the large forces and pressures which accompany the air pollutants at the moment of release (Emetere, 2014). The study assumed an average directional diffusivity of $1720 \mathrm{~m}^{2} \mathrm{~s}^{-1}$ which is about $25 \%$ of the average generated speed of common explosives. The model revealed a plume cloud impact of $6.8 \times 10^{7} \mu \mathrm{gm}^{-3}$ at the emission point source in the first 1 millisecond $(0.01 \mathrm{~s})$ that decayed suddenly to a value of $1.7 \times 10^{7} \mu \mathrm{gm}^{-3}$ in the first 1 deci-second $(0.1 \mathrm{~s})$ and by the end of the first one second $(1.0 \mathrm{~s})$, the impact concentration at the emission point source was $3.2 \times 10^{5} \mu^{g^{-3}}$. This implied a $99.5 \%$ sudden dispersion of the matters released at the emission point source within the shortest possible time. This almost instant dispersion of air pollutants and displacement of air parcel in the immediate vicinity of the emission point source are associated with the extreme forces and pressures generated by the blast. This aided the propagation of the air pollutants emitted both horizontally and vertically at the shortest time frame. The model revealed that the rate of dispersion of the air pollutants depended directly on the associated mass of the pollutants, the speed and the momentum generated by the blast. Thus, the kinetic energy associated with the blast played more significant role in the almost instant dispersion from the point source than the prevalent atmospheric conditions as would have been the case for normal emissions.

The model revealed that an infinitesimal fraction of a second of the explosion was very significant as the result has shown in Fig. 3a and b. The sharp variation of concentration impact at the source from $1.7 \times 10^{7} \mu^{-3} \mathrm{gm}^{-3}$ in the first 1 deci-second $(0.1 \mathrm{~s})$ to $3.2 \times 10^{5} \mu \mathrm{gm}^{-3}$ by the end of the first one second $(1.0 \mathrm{~s})$ and to just $300 \mu \mathrm{gm}^{-3}$ by the end of the first one minute $(60.0 \mathrm{~s})$ was a pointer to the rapid decay which might not be easy to observe under real physical conditions, but only in virtual experimentation as performed in this study.

\section{Discussion}

It can thus be suggested that air pollutants emission from sudden explosion is more of forceful injection into the atmosphere than gradual dispersion in the very few seconds of the blast occurrence and like air pollutants from volcanic eruption, it also has capacity to penetrate higher altitude of the atmosphere at shorter time than normally released air pollutants would do. The eruption of Mount Pinatubo in June 1991 was found to have made significant chemical perturbation to the ozone layer and the resulting observed depletion in the ozone concentration for that period (Groisman, 1992). Likewise, Kane (1998) noted the occurrence of a spectacular Quassi Biennial Oscillation (QBO) wave between 1991 and 1993 with a range of about $\pm 10 \%$ which he associated partly with the volcanic eruptions of Mount Pinatubo in June 1991. Similarly, Morris et al. (2003) observed significant increase in stratospheric chlorine, which was linked with the El Chichon eruption in 1982. The aerosols ejected into stratosphere forms different layer to increase its adverse effect (Emetere et al., 2015a; 2015b). 


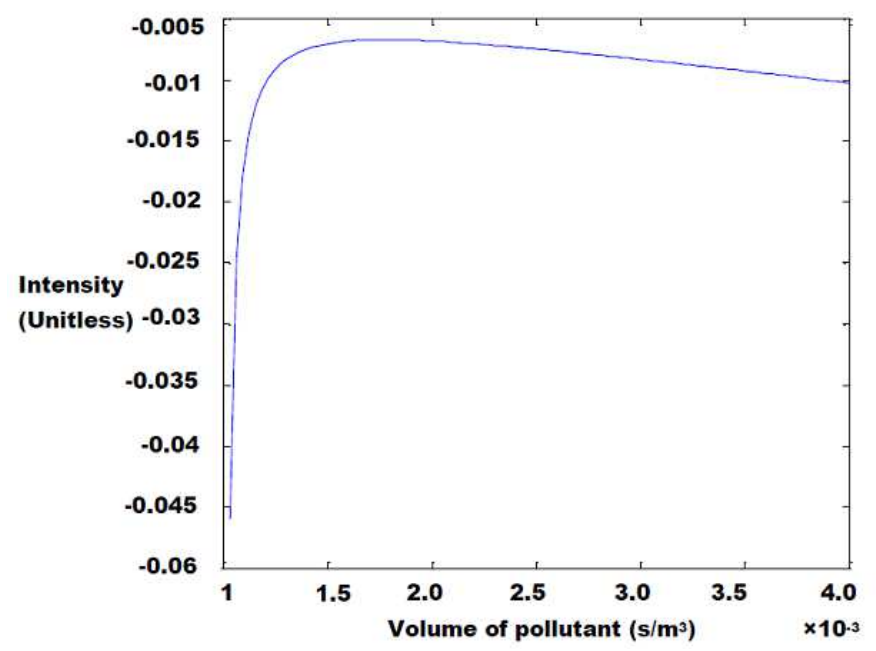

Fig. 1. Mathematical relationship between intensity and other parameters in Equation 8

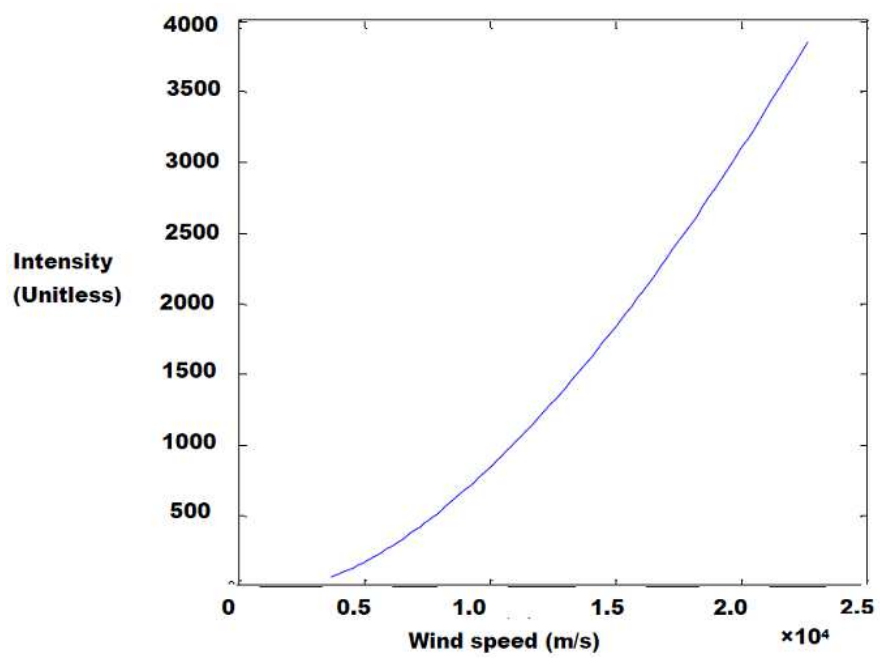

Fig. 2. Mathematical relationship between intensity other parameters in Equation 9
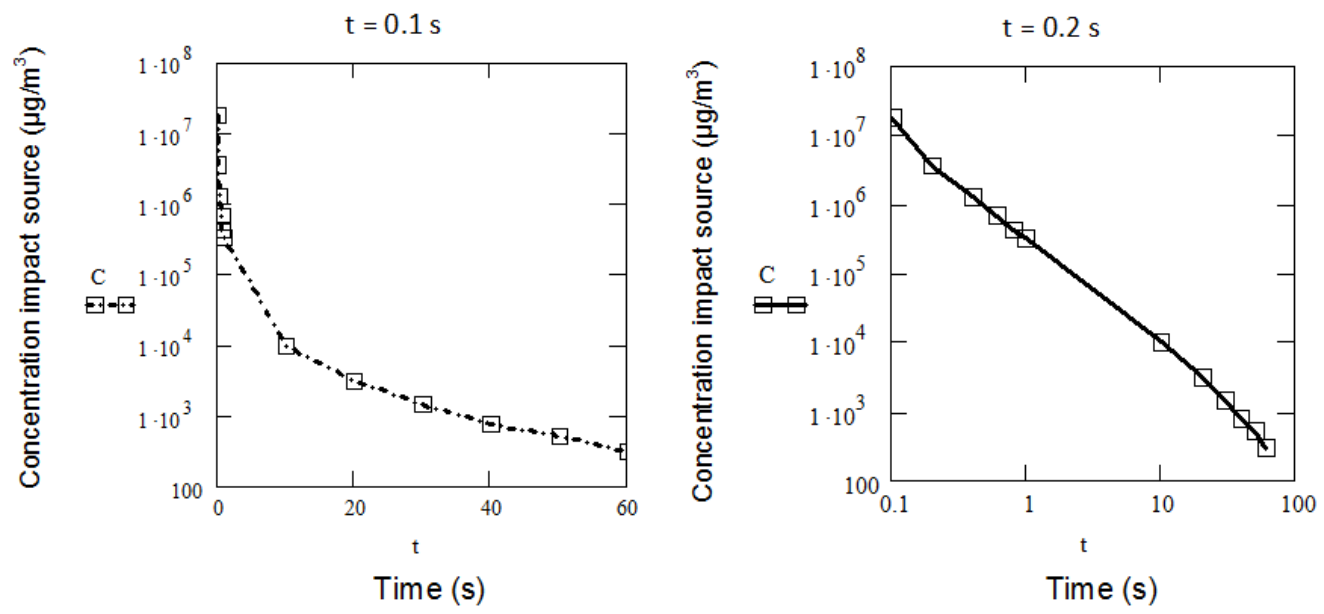

Fig. 3. Variation of concentration impact at emission point source in the first one minute $(60 \mathrm{~s})$ of blast 

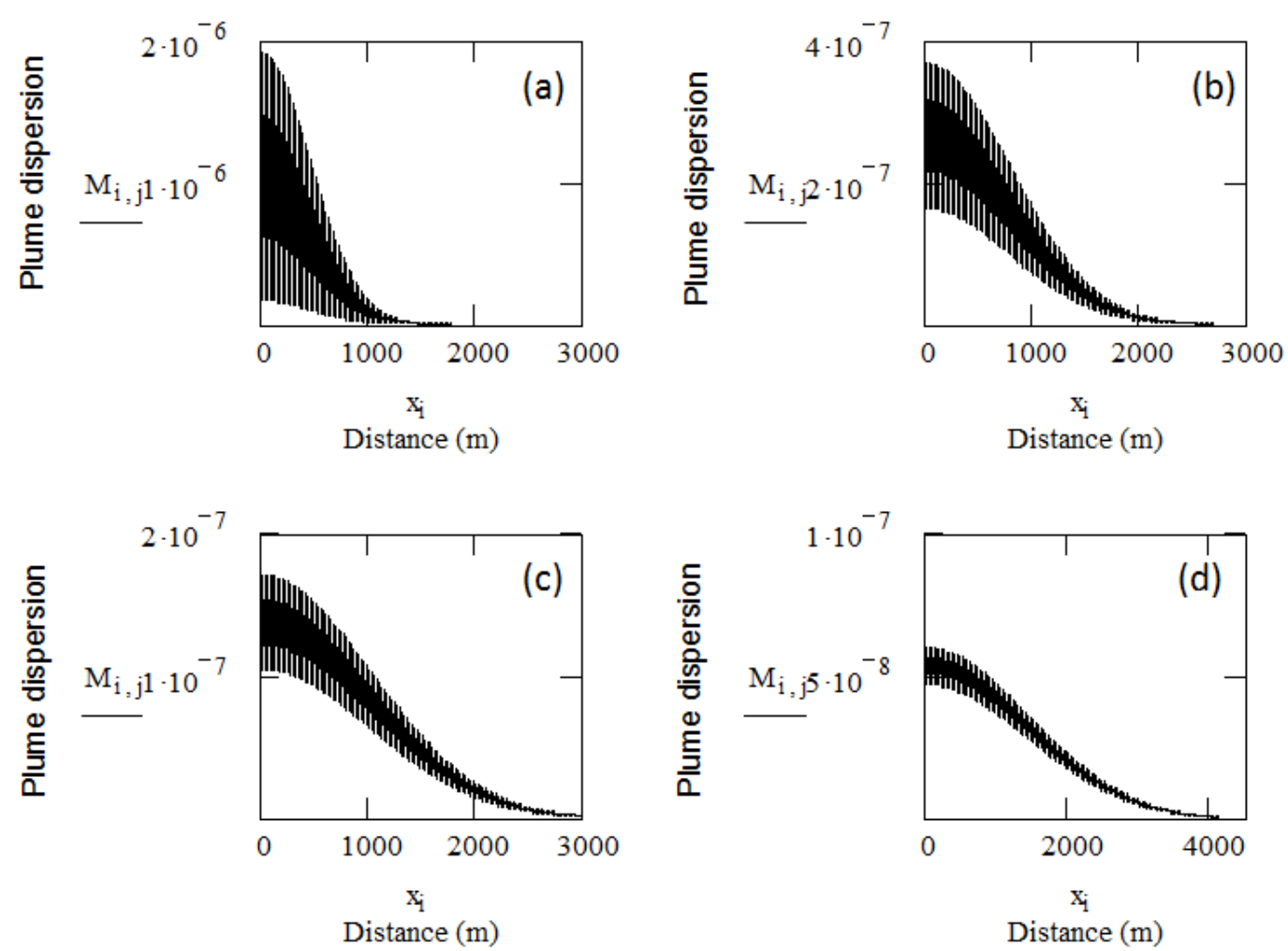

Fig. 4. Long range air pollution dispersion $\left(\mathrm{kgm}^{-3}\right)$ in 1, 3, 5 and 10 min of blast, respectively

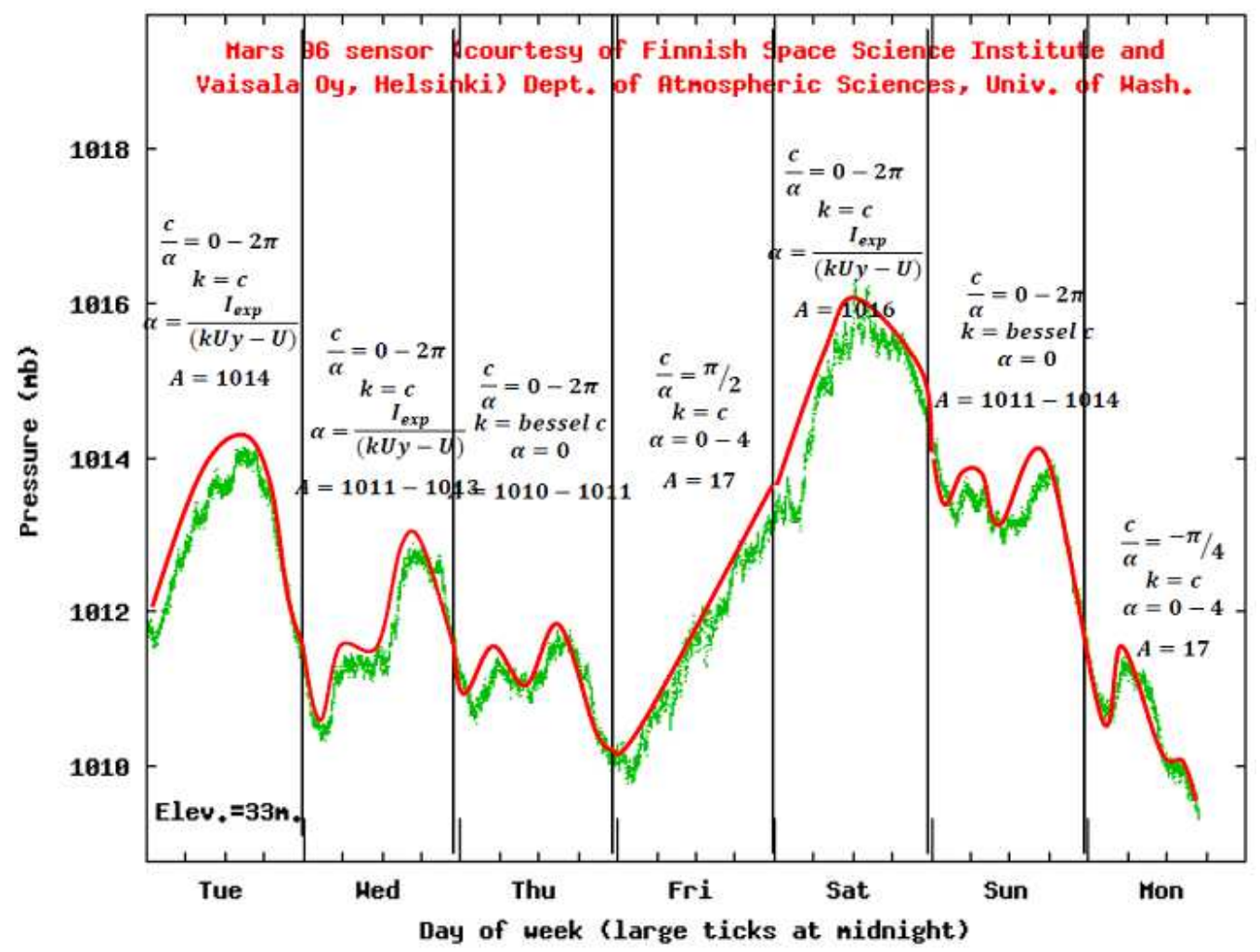

Fig. 5. Day-to-day atmospheric pressure variation 
Thus, it can be inferred that because of the ability of air pollutants from sudden explosion to reach higher altitudes fast, they have both immediate and long term adverse effect on the environment and the life form on the earth. Thus, air pollutant from sudden blast is a further complication on the already existing air pollution challenge confronting the environment.

Further investigations carried out revealed that the long range air pollutant dispersion from sudden explosion modelled has the ability to reach a distance of $1.2 \mathrm{~km}$ within the first minute of the explosion and could be propagated as far as $4 \mathrm{~km}$ within the first ten to fifteen minutes of the release (Fig. 4). Equation 14 was tested using the pressure data acquired from the 'Mars 96 sensor' to analyze a large tick at midnight within a week. The values of the constants were worked out for each day as shown in Fig. 5. The value of each constant represents the effect of various climatic conditions needed to aid the propagation of pollutants. The varying constants observed for each day suggests that the speed of air pollutant dispersion is dependent on other factors which might not have been captured by previous research on volcanic blast waves.

\section{Conclusion}

This study revealed that like volcanic eruptions, air pollution from sudden blast is more of forceful injection into the atmosphere than gradual dispersion in the first few seconds of the explosion. The forceful injection which has been traced to the explosion intensity, pressure and volume of the air pollutant emitted is also influenced by the prevailing wind field. This suggests that another way of controlling the flow of air pollutants from anthropogenic sources (or otherwise) is to work-out an inversion mathematical process using Equation 14 only if various constants are properly calculated as shown in Fig. 5. The application of our theory (Equation 14) to large tick dispersion at midnight suggests the existence of other influencing environmental factors aside the Coriolis, pressure gradient force and friction which has not been captured in volcanic blast transmission in form of air pollutants. In this study, a sudden decay of the concentration dimensional impact at source point from $1.7 \times 10^{7}$ to $300{\mu \mathrm{gm}^{-3}}^{-3}$ in the first $60 \mathrm{~s}$ was obtained. Sudden injection of air pollutants into the atmosphere is enhanced by the enormous pressure and momentum generated by the blast. The ability of air pollutants from sudden explosion to reach higher altitudes within a short period of time made it to have both immediate and long term adverse effect on the environment and life form. This implies a further complication of the already existing air pollution challenge confronting the environment.

\section{Acknowledgement}

The authors appreciate the Finnish Space Science Institute for using their data for analysis. He authors declare that they have no competing interests.

\section{Funding Information}

The authors gratefully acknowledge the partial funding of Covenant University, Ota-Nigeria.

\section{Authors' Contributions}

Maevel Lola Akinyemi: Did the framework of the research i.e., initial write-up and some simulation.

Moses Eterigho Emetere: Did the mathematical derivations and simulations.

Mojisola Rachel Usikalu: Edited the manuscript.

\section{Ethics}

This article is original and contains unpublished material. The corresponding author confirms that all of the other authors have read and approved the manuscript and no ethical issues involved.

\section{References}

Arya, P., 1999. Air Pollution Meteorology and Dispersion. 1st Edn., Oxford University Press, New York, ISBN-10: 0195073983, pp: 310.

Bazarov, S.B., V. Bazhenova, O.V. Bulat, V.V. Golub and R.A.M. Shulmeiste, 1991. Three-dimensional diffraction of shock wave. Proceedings of the 18th International Symposium on Shock Waves, Sendai, Japan, Jul. 21-26, Springer Berlin Heidelberg, pp: 251-254. DOI: 10.1007/978-3-642-77648-9 34

Bluth, G.J.S., S.D. Doiron, C.C. Schnetzler, A.J. Krueger and L.S. Walter, 1992. Global tracking of the $\mathrm{SO}_{2}$ clouds from the June, 1991 Mount Pinatubo eruptions. Geophys. Res. Lett., 19: 151-154. DOI: 10.1029/91GL02792

Devine, J.D., H. Sigurdsson, A.N. Davis and S. Self, 1984. Estimates of sulfur and chlorine yield to the Atmosphere from volcanic eruptions and potential climatic effects. J. Geophys. Res., 89: 6309-6325. DOI: 10.1029/JB089iB07p06309

DiGiovanni, F. and P. Fellin, 2006. Transboundary Air Pollution. In: Environmental Monitoring, Inyang, H.I. and J.L. Daniels (Eds.), Eolss Publishers, Oxford, UK.

Groisman, P.Y., 1992. Possible regional climate consequences of the Pinatubo eruption: An empirical approach. Geophys. Res. Lett., 19: 1603-1606. DOI: 10.1029/92GL01474

Hagerty, M.T., S.Y. Schwartz, M.A. Garces and M. Protti, 2000. Analysis of seismic and acoustic observations at Arenal volcano, Costa Rica, 1995-1997. J. Volcanol. Geothermal Res., 101: 27-65. DOI: $10.1016 / \mathrm{S} 0377-0273(00) 00162-1$ 
Hopke, P.K., 2009. Contemporary threats and air pollution. Atmospheric Environ., 43: 87-93. DOI: 10.1016/j.atmosenv.2008.09.053

Kane, R.P., 1998. Ozone depletion, related UV-B increase and increase skin cancer incidences. Int. J. Climatol., 18: 457-457.

McCormick, M.P. and T.J. Swissler, 1983. Stratospheric aerosol mass and latitudinal distribution of the El Chichon eruption cloud for October 1982. Geophys. Res. Lett., 10: 877-880.

DOI: 10.1029/GL010i009p00877

Emetere, M.E., 2012. Monitoring and prediction of earthquakes using simulated temperature deviation curve model. Int. J. Applied Inform. Syst., 4: 13-17. DOI: $10.5120 /$ ijais12-450659

Emetere, M.E. and M.L. Akinyemi, 2013. Modeling of generic air pollution dispersion analysis from cement factory. Analele Universitatii din OradeaSeria Geografie, 628: 181-189.

Emetere, M.E., 2013. Modeling of particulate radionuclide dispersion and deposition from a cement factory. Ann. Environ. Sci., 7: 71-77.

Emetere, M.E., 2014. Theoretical forecast of the health implications of citing nuclear power plant in Nigeria. J. Nuclear Particle Phys., 4: 87-93. DOI: $10.5923 /$ j.jnpp.20140403.01

Emetere, M.E., M.L. Akinyemi and O. Akin-Ojo, 2015a. Aerosol optical depth trends over different regions of Nigeria: Thirteen years analysis, Modern Applied Sci., 9: 267-279. DOI: 10.5539/mas.v9n9p267

Emetere, M.E., M.L. Akinyemi and O. Akinojo, 2015b. Parametric retrieval model for estimating aerosol size distribution via the AERONET, LAGOS station. Environ. Pollut., 207: 381-390. DOI: 10.1016/j.envpol.2015.09.047

Morris, G., G. Barbara, P.A. Newman, A. Aikin and W. Heaps et al., 2003. The chemical, thermal and dynamical structure of earth's atmosphere.

Neff, M., 1998. A visual model for blast waves and fracture. PhD Thesis, University of Toronto.
Balmforth, N.J., R.V. Craster and A.C. Rust, 2005. Instability in flow through elastic conduits and volcanic tremor. J. Fluid Mechan., 527: 353-377. DOI: $10.1017 / \mathrm{S} 0022112004002800$

Perovich, S.M., 2001. Concerning contribution to the special trans function theory. University of Montenegro.

Read, W.G., L. Froidevaux and J.W. Waters, 1993. Microwave limb sounder measurement of stratospheric $\mathrm{SO}_{2}$ from the Mt. Pinatubo volcano. Geophys. Res. Lett., 20: 1299-1302. DOI: 10.1029/93GL00831

Seinfeld, J.H., 1986. Atmospheric Chemistry and Physics of Air Pollution. 1st Edn., John Wiley and Sons, New York, ISBN-10: 0471828572, pp: 738.

Slotnick, J., 2008. Explosive forces of improvised explosive devices.

Smith, S.J., H. Pitcher and T.M.L. Wigley, 2001. Global and regional anthropogenic sulfur dioxide emissions. Global Planetary Change, 29: 99-119. DOI: 10.1016/S0921-8181(00)00057-6

Smodis, B., 2007. Investigation of trace element atmospheric pollution by nuclear analytical techniques at a global scale: Harmonised approaches supported by the IAEA. J. Environ. Manage., 85: 121-128. DOI: 10.1016/j.jenvman.2006.08.007

Tupper, A., S. Carn, J. Davey, Y. Kamada and R. Potts et al., 2004. An evaluation of volcanic cloud detection techniques during recent significant eruptions in the western 'ring of fire'. Remote Sens. Environ., 91: 27-46. DOI: $10.1016 /$ j.rse.2004.02.004

Tupper, A. and R. Wunderman, 2009. Reducing discrepancies in ground and satellite-observed eruption heights. J. Volcanol. Geothermal Res., 186: 22-31. DOI: 10.1016/j.jvolgeores.2009.02.015

Walker, G.P.L., 1980. The Taupo pumice: Product of the most powerful known (Ultraplinian) eruption. J. Volcanol. Geothermal Res., 8: 69-94. DOI: $10.1016 / 0377-0273(80) 90008-6$ 